\title{
Short-Term Intraocular Pressure Response to the Combined Effect of Transcutaneous Electrical Nerve Stimulation over Acupoint (Acu-TENS) and Yoga Ocular Exercise in Type 2 Diabetic Patients with Primary Open- Angle Glaucoma: A Randomized Controlled trial
}

\author{
Ali Mohamed Ali Ismail ${ }^{1, *}$, Alshaymaa Shaaban Abd El-Azeim ${ }^{2}$ \\ ${ }^{1}$ Department of Physical Therapy for Cardiovascular/Respiratory Disorder and Geriatrics, Faculty of Physical Therapy, Cairo University, \\ Giza, Egypt \\ ${ }^{2}$ Basic Science Department, Faculty of Physical Therapy, Cairo University, Giza, Egypt
}

Received March 8, 2021

Revised July 2, 2021

Accepted August 24, 2021

Correspondence to Ali Mohamed Ali Ismail Department of Physical Therapy for Cardiovascular/Respiratory Disorder and Geriatrics, Faculty of Physical Therapy, Cairo University, Giza, Egypt E-mail ali.mohamed@pt.cu.edu.eg
Background: Despite the adherence to medications, the control of the modifiable key risk factor-intraocular pressure (IOP) - for the progression of primary open-angle glaucoma (POAG) in diabetics is usually difficult; hence, many glaucoma patients try other alternative therapeutic options.

Objectives: This randomized controlled study investigated the short-term IOP response to the combined effects of transcutaneous electrical nerve stimulation over acupoint (AcuTENS) and yoga ocular exercise in type 2 diabetics with POAG.

Methods: Eighty diabetics with bilateral POAG, ages $\geq 50$ years, IOP $>21 \mathrm{mmHg}$ in both eyes, and a body mass index below $30 \mathrm{~kg} / \mathrm{m}^{2}$ were included in this trial. The patients were randomly assigned to group $A$ ( $n=40$; this group received 20 minutes of yoga ocular exercise followed by 20 minutes of active Acu-TENS over bilateral BL 61 and BL 62 acupoints) and group $B(n=40$; this group received the same protocol as group A but with a placebo Acu-TENS). The repeated measurement of IOP were recorded before, immediately after, 30 minutes, and 60 minutes after the sessions.

Results: The repeated measures analysis of variance revealed a greater significant decline of IOP in group A than group $B$ in both eyes at the consecutive intervals of time measurements.

Conclusion: According to this short-term observation, the addition of Acu-TENS to yoga ocular exercise could reduce the high IOP in diabetic patients with POAG, but further longterm trials are needed.

Keywords: Yoga ocular exercise, Transcutaneous electrical nerve stimulation, Primary open-angle glaucoma, Intraocular pressure, Type 2 diabetes mellitus

\section{INTRODUCTION}

Type 2 diabetes mellitus (T2DM) is associated with many microvascular and neuropathic deteriorative consequences in all body parts [1], including the eye, which usually may develop primary open-angle glaucoma (POAG), the most frequent recognizable type of all forms of glaucoma, in response to poor glycemic control [2]. POAG is associated with an open anterior chamber angle by gonioscopy and is a common disease in both eyes characterized by progressive degenerative damage to the axons of the optic nerve and preferential loss of retinal ganglion cells [3]. After cataracts, glaucoma affecting about 68 million people worldwide and is considered the second causative leading factor for visual loss [4].

POAG induced by T2DM may be aggravated by hyperglycemia and higher levels of intraocular pressure (IOP) due to multiple mechanisms, including a changed osmotic gradient that moves more aqueous humour to the anterior chamber of the eye, the interrupted function of the ocular trabecular meshwork, the increased thickness of cornea, a reduced retinal blood and oxygen supply due to the 
microvascular damage of the retina and optic neuronal fibers, and disturbed retinal vascular autoregulation (RVA). RVA defends against the fluctuations of IOP. [5].

The tight and continuous control of IOP is still the only applicable therapeutic solution to slow the progression of POAG in diabetic patients [6]. The mainline treatment focuses on the application of IOP-descending eye drops which, despite several drug combinations, do not lower the IOP to the recommended normal range of $10-21 \mathrm{mmHg}$ [7]. To support the usual use of prescribed agents, many patients prefer the complementary therapies [8] for POAG, such as meditation [9], yoga [10], and acupuncture [11].

Despite the common use of yoga as a complementary therapy in the treatment of many chronic disorders to rebalance the emotions, mind, and harmony between the different body parts [12], specific techniques of yoga, such as down-head yogic postures, are not recommended because they elevate the episcleral venous pressure that increases IOP [13] in healthy persons [14] and glaucomatous patients [15]. After the reported IOP decrease in healthy subjects [16], Yoga ocular exercise has been advised by many yoga practitioners to preserve the natural health and well-being of eyes in POAG [17].

With the suggested mechanism related to the decrease in IOP being the regained rebalance of qi (the Chinese traditional definition of energy or vital force passing through meridians) via stimulating specific acupoints on the body's surface, acupuncture is commonly used as an alternative treatment for POAG [18]. Despite the popular acupoint stimulation by manual or electro-acupuncture needling [19], both methods are invasive and consequently involve some injury risk. Non-invasive transcutaneous electrical nerve stimulation over acupoints (Acu-TENS) is supposed to produce the same effect of both methods [20], especially when used to treat eye disorders, such as glaucoma with IOP $>21 \mathrm{mmHg}$, related to the Bladder Meridian (BL) FootTaiyang [21]. However, to the best of our knowledge following an extensive literature review, Acu-TENS's effectiveness on elevated IOP levels in type-2 diabetics with POAG has not tested been before.

BL Foot-Taiyang is the longest meridian in the whole body and travels from the inner eye canthus to the top of the head before descending on the posterior aspect of the back and lower limbs to end on the lateral aspect of the little toe. The pathway of the BL Foot-Taiyang matches the drainage pathway of the aqueous humour of the eye (higher IOP is reduced after the increased drainage of the aqueous humour from the eye) [21].

Despite the promising and attractive roles of Acu-TENSand yoga-based interventions as alternative and complementary therapies in IOP reduction $[10,21]$, the combined effects of both interventions on IOP in diabetics with glaucoma have not been studied before. To our knowledge, this is the first study to investigate the short-term combined effects of Acu-TENS and yoga ocular exercise on IOP in type 2 diabetic patients with POAG.

\section{MATERIALS AND METHODS}

\section{Study design}

This trial was a single-center, prospective, assessor/ participant (double) blinded, and randomized controlled study that followed all guidelines set forth by the Declaration of Helsinki. Eighty patients were randomly chosen from the ophthalmology out-patient clinics of Om El-Masryeen, Cairo University, Bulaq Al-Dakrour, Mansheyet El-Bakry, and Ain Shams University Hospitals. The patients were referred to the in-Cairo private center of physiotherapy in which the study was conducted.

\section{Ethics}

The study was performed during the period from 20 November 2020 to 1 February 2021. P.T.REC/012/002604 was the agreement code obtained from the ethical scientific board of the Physical Therapy Faculty, Cairo University before the study was conducted. NCT04645992 is this trial's registered number on https://www.clinicaltrials.gov/. The patients (46 females and 34 males) signed the approved consent by the College of Physiotherapy, Cairo University before participation in this trial.

\section{Inclusive and exclusive criteria}

Eighty diabetic patients with a bilateral mild or moderate POAG, DM duration $>5$ years, ages $\geq 50$ years old, IOP more than $21 \mathrm{mmHg}$ in both eyes, and a body mass index (BMI) less than $30 \mathrm{~kg} / \mathrm{m}^{2}$ were included in this research. Patients with acute or chronic inflammatory eye disorders, other IOPelevating eye disorders, IOP-descending medications, laser surgical therapeutic procedures for myopia or glaucoma, previous yoga and/or any type of complementary therapies within the past 3 months, malignant disorders, cataracts, other systemic diseases, and mental or psychological disorders were excluded by an ophthalmologist from the recruitment. The patients were randomly assigned to group A (80 eyes) and group B (80 eyes).

\section{Program of intervention}

Every patient in both groups received only one session of 20 min yoga ocular exercises followed immediately by a $20 \mathrm{~min}$ direct current (DC) Acu-TENS on bilateral BL61 acupoints (BL61 sited on the lateral foot side, posterior and distal to the lateral malleolus, lateral to the calcaneal bone at the red and 
white skin junction) and bilateral BL62 acupoints (BL62 sited in the depression directly below the lateral malleolus). The yoga ocular exercises were performed under the supervision of a certified yoga trainer. The exercises were initiated with a short technique for relaxation (breathing), Tratak exercise (the patient was ordered to continuously concentrate his/her gaze on an inflamed candle for $60 \mathrm{~s}$ ), blinking, viewing (diagonal, front, rotational, and sideway viewing) [12], and palming exercise of eyes (palming was performed by ordering the patient to rub both palms against each other; then, each palm was placed on the ipsilateral eye to warm it without applying firm pressure to the balls of the eye) [16]. The electrodes of an active Acu-TENS unit (DC, Phyaction 740, Uniphy BV, Netherlands) were placed on the bilateral BL61 and BL62 acupoints for $20 \mathrm{~min}$ in group A while the same Acu-TENS unit was placed on a placebo position on the same acupoints in group B. For group B, with the Acu-TENS unit out of sight for the glaucoma patients, the Acu-TENS unit was turned on with a non-perceptible stimulation for $20 \mathrm{~min}$, and every glaucoma patient was told that he/she would not feel anything during the Acu-TENS treatment.

\section{Outcome measure}

Besides the baseline assessment, IOP was measured immediately, $30 \mathrm{~min}$, and $60 \mathrm{~min}$ after the end of the intervention in both groups using the Goldman Applanation Tonometer between 7 am to 8 am to avoid the IOP fluctuation caused by the circadian rhythm (maximal IOP value occurs at daybreak while the minimum value occurs at the end of the afternoon) [22]. The assessor (person who assessed the IOP outcome) did not know the type of interventions or the treatment group to which the glaucoma patients belonged, either before or after timed treatment measurements.

\section{Sample size calculation}

With version 3.1.9.2 of the $G^{\star}$ Power program, a priori sample size analysis estimated a 0.31 effect size of the target outcome variable, IOP. This effect size was based on the F test of the repeated multivariate analysis of variance (MANOVA) measurement done on a 10 -subject pilot study with a $5 \%$ type I error rate (alpha level 0.05 ) at $85 \%$ of the power, and correlation among repetition measures was 0.5 . The results of this analysis detected the required minimum sample size as being 74 glaucomatous patients.

\section{Randomization}

Diabetic glaucomatous patients who showed an interest in participating in this study were met with first. The sequenced random allocation was produced via SPSS (version 23.0; IBM Corp, New York, USA) by an independent physiotherapy researcher and placed in closed opaque envelopes to gua- rantee allocations were hidden. The closed envelope of every eligible patient was unclosed by the nurse immediately before the application of the treatment during the session.

\section{Blinding}

This trial was a patient- and outcome-assessor blinded randomized controlled study. All participating patients were not aware of their assigned group or intervention in this trial.

\section{Statistical analysis}

Using version 23 of SPSS (IBM Corp, New York, USA), the Shapiro-Wilk test proved the normal distribution of IOP and baseline data (age, weight, height, BMI, Glycated hemoglobin Alc [HbAlc], duration of type 2 diabetes), so all variables were analyzed by parametric tests with a $p$-value significance less than 0.05. Repeated measures analysis of variance (ANOVA) was used to detect the effects of the treatment, the treatment time, and the interaction between treatment and time. Multiple pairwise comparisons by Tukey's tests were used to compare between groups, and paired t-tests were used to compare between pre- and post-treatment within groups. For the assessment of the sphericity, Mauchly's test was used, and the $p$-value was 0.058 , so there was no violation in sphericity.

\section{RESULTS}

\section{Baseline data}

From 120 screened patients, only 80 patients were assigned randomly to the two groups (Fig. 1).

Regarding the age, weight, height, BMI, duration of type 2 diabetes, and $\mathrm{HbAlc}$, there was a non-significant difference between both groups after the unpaired T analysis. Furthermore, regarding the sex distribution, the chi-squared test revealed a non-significant difference between the two studied groups (Table 1).

\section{Results of IOP in the right and left eyes}

Repeated measures ANOVA was utilized to determine the effects of both the treatment and time between groups A and $B$ in the right and left eyes. Regarding the time, Wilks' Lambda test reported a significant statistical difference in the left and right eyes with a $p$-value $=0.0001$, and F-value $=66.36$. Furthermore, regarding the treatment, there was a significant statistical difference between both groups, as the $p$-value $=$ 0.0001 , and F-value $=35.64$. Finally, regarding the interaction between time and group, there was a significant statistical difference, as the $p$-value $=0.0001$, and $\mathrm{F}=14.86$.

Regarding IOP in the right and left eyes, between-group multiple pairwise comparisons-extracted from the repeated measures ANOVA-revealed no significant pre-treatment 


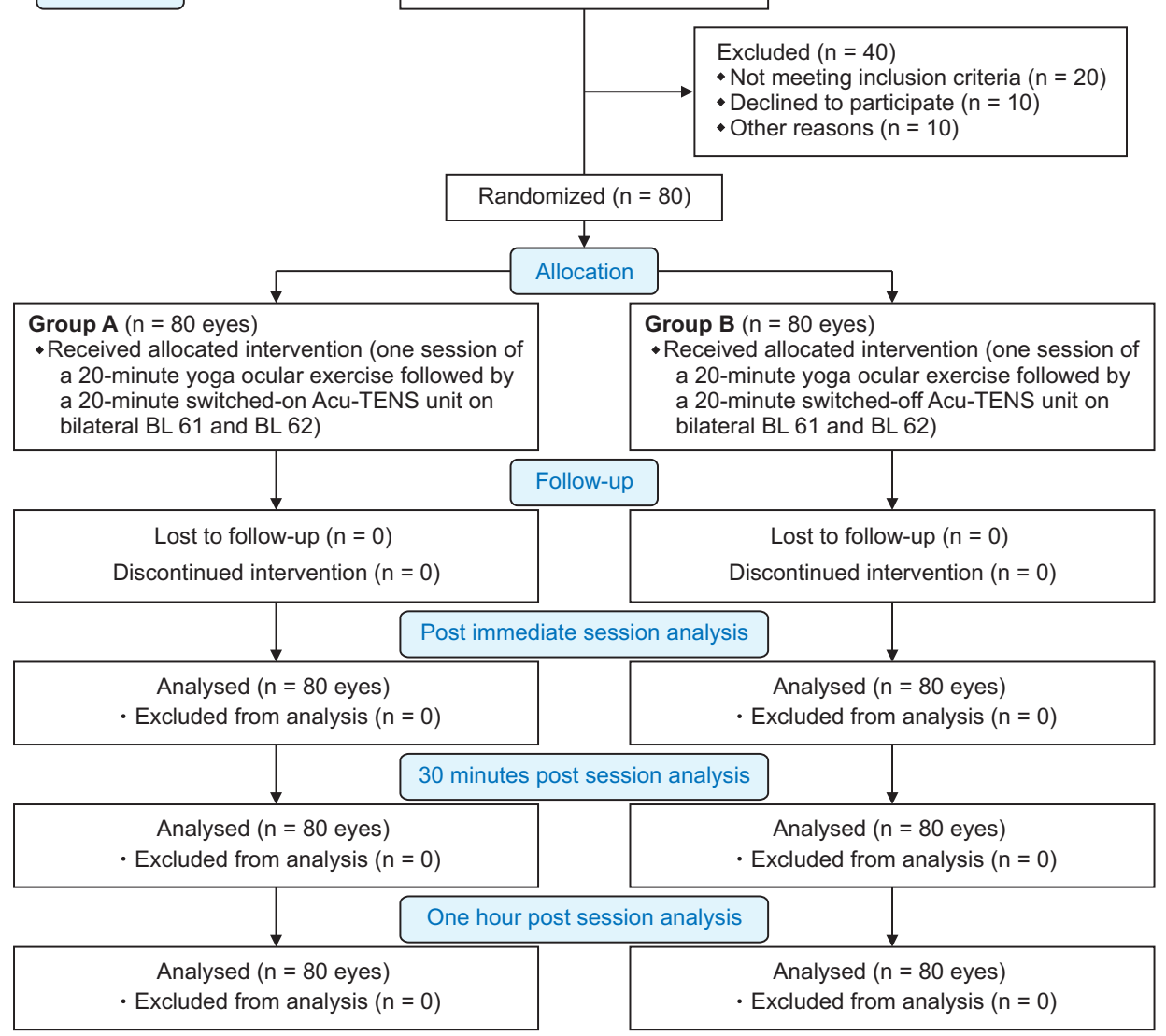

Fig. 1. Consort flow diagram of the study.

Table 1. Demographic data of groups

\begin{tabular}{lccrr}
\hline & $\begin{array}{c}\text { Group A } \\
\text { Mean } \pm \text { SD }\end{array}$ & $\begin{array}{c}\text { Group B } \\
\text { Mean } \pm \text { SD }\end{array}$ & T-value & $p$-value \\
\hline Age (year) & $56.77 \pm 2.74$ & $57.37 \pm 2.45$ & -1.03 & $0.31^{\mathrm{a}}$ \\
Sex* & $(19 \mathrm{M}, 21 \mathrm{~F})$ & $(15 \mathrm{M}, 25 \mathrm{~F})$ & 0.81 & $0.36^{\mathrm{a}}$ \\
Weight $(\mathrm{kg})$ & $78.75 \pm 4.16$ & $79.67 \pm 6.36$ & -0.77 & $0.44^{\mathrm{a}}$ \\
Height $(\mathrm{m})$ & $168.82 \pm 5.82$ & $169.55 \pm 4.82$ & -0.62 & $0.53^{\mathrm{a}}$ \\
BMI $\left(\mathrm{kg} / \mathrm{m}^{2}\right)$ & $27.66 \pm 1.56$ & $27.71 \pm 1.88$ & -0.10 & $0.92^{\mathrm{a}}$ \\
HbA $_{1} \mathrm{C} \%$ & $9.72 \pm 0.84$ & $9.92 \pm 0.69$ & -1.15 & $0.25^{\mathrm{a}}$ \\
Duration of DMT2 (year) & $6.16 \pm 1.16$ & $6.52 \pm 1.04$ & -0.52 & $0.61^{\mathrm{a}}$
\end{tabular}

${ }^{a}$ not significant; ${ }^{*}$ Chi-Square test; $\mathrm{SD}=$ standard deviation; $p=$ probability; $\mathrm{BMI}=$ body mass $_{\text {index; }} \mathrm{HbA}_{1} \mathrm{C}=$ glycated hemoglobin; $\mathrm{kg}=$ kilogram; $\mathrm{m}=$ meter; $\mathrm{M}=$ male; $\mathrm{F}=$ female; DMT2 = diabetes mellitus type 2 ; group $\mathrm{A}=\mathrm{Acu}$-TENS + yoga exercises; Group B = placebo TENS + yoga exercises.

difference, as the $p$-value $>0.05$, but there was a statistically significant difference between groups in the different IOP measurement times, as the $p$-value $<0.05$. Within-group IOP analysis in the right and left eyes showed there was a statistical significance between the pre-treatment and different intervals of post-measurements, as the $p$-value $>0.05$ showed superiority to group A in both eyes (Table 2 and 3 ).

\section{DISCUSSION}

The results of this study showed a short-term decline in IOP in response to active Acu-TENS treatment when added to yoga ocular exercise in diabetic patients with POAG. The mechanism explaining IOP decline after yoga ocular exercise had not been fully elucidated until now due to the lack of research regarding this subject.

The eyes are constantly moved with minimal deviations 
Table 2. Between- and within-group IOP analysis (right eye)

\begin{tabular}{|c|c|c|c|}
\hline Right eye & $\begin{array}{c}\text { Group A } \\
\text { Mean } \pm \text { SD }\end{array}$ & $\begin{array}{c}\text { Group B } \\
\text { Mean } \pm \text { SD }\end{array}$ & $p$-value \\
\hline \multicolumn{4}{|l|}{$\mathrm{IOP}(\mathrm{mmHg})$} \\
\hline Pre-treatment & $26.52 \pm 1.81$ & $27.05 \pm 1.55$ & $0.17^{\mathrm{a}}$ \\
\hline Immediately after & $23.67 \pm 1.42$ & $26.07 \pm 1.46$ & $0.0001^{b}$ \\
\hline$p$-value (within-group) & $0.0001^{\mathrm{b}}$ & $0.0001^{\mathrm{b}}$ & \\
\hline$\%$ of improvement & $10.7 \%$ & $3.6 \%$ & \\
\hline \multicolumn{4}{|l|}{ IOP $(\mathrm{mmHg})$} \\
\hline Post 30 minutes & $23.47 \pm 1.46$ & $25.97 \pm 1.51$ & $0.0001^{b}$ \\
\hline$p$-value (within-group) & $0.0001^{b}$ & $0.0001^{\mathrm{b}}$ & \\
\hline$\%$ of improvement & $11.5 \%$ & $4 \%$ & \\
\hline \multicolumn{4}{|l|}{$\mathrm{IOP}(\mathrm{mmHg})$} \\
\hline Post 60 minutes & $23.35 \pm 1.42$ & $25.92 \pm 1.55$ & $0.0001^{b}$ \\
\hline$p$-value (within-group) & $0.0001^{b}$ & $0.0001^{\mathrm{b}}$ & \\
\hline$\%$ of improvement & $12 \%$ & $4.2 \%$ & \\
\hline
\end{tabular}

${ }^{a}$ no significance difference; ${ }^{b}$ significance difference; IOP = intra ocular pressure; $\mathrm{SD}=$ standard deviation; $\mathrm{mmHg}=\mathrm{millimeter}$ mercury; $p=$ probability; Group A = Acu-TENS + yoga exercises; Group B = placebo TENS + yoga exercises.

Table 3. Between- and within-group IOP analysis (left eye)

\begin{tabular}{|c|c|c|c|}
\hline Left eye & $\begin{array}{c}\text { Group A } \\
\text { Mean } \pm \text { SD }\end{array}$ & $\begin{array}{c}\text { Group B } \\
\text { Mean } \pm \text { SD }\end{array}$ & $p$-value \\
\hline \multicolumn{4}{|l|}{ IOP (mmHg) } \\
\hline Pre-treatment & $27.07 \pm 1.63$ & $27.47 \pm 1.37$ & $0.24^{\mathrm{a}}$ \\
\hline Immediately after & $24.10 \pm 1.58$ & $26.40 \pm 1.48$ & $0.0001^{b}$ \\
\hline$p$-value (within-group) & $0.0001^{\mathrm{b}}$ & $0.001^{\mathrm{b}}$ & \\
\hline$\%$ of improvement & $11 \%$ & $4 \%$ & \\
\hline \multicolumn{4}{|l|}{ IOP (mmHg) } \\
\hline Post 30 minutes & $23.85 \pm 1.67$ & $26.30 \pm 1.63$ & $0.0001^{b}$ \\
\hline$p$-value (within-group) & $0.0001^{b}$ & $0.0001^{b}$ & \\
\hline$\%$ of improvement & $12 \%$ & $4.2 \%$ & \\
\hline \multicolumn{4}{|l|}{ IOP (mmHg) } \\
\hline Post 60 minutes & $23.57 \pm 1.67$ & $26.20 \pm 1.71$ & $0.0001^{b}$ \\
\hline$p$-value (within-group) & $0.0001^{b}$ & $0.0001^{b}$ & \\
\hline$\%$ of improvement & $13 \%$ & $4.6 \%$ & \\
\hline
\end{tabular}

${ }^{a}$ no significance difference; ${ }^{b}$ significance difference; IOP = intra ocular pressure; $\mathrm{SD}=$ standard deviation; $\mathrm{mmHg}=\mathrm{millimeter}$ mercury; $p$ = probability; Group A = Acu-TENS + yoga exercises; Group B = placebo Acu-TENS + yoga exercises.

from the main position throughout the day and to some degree during the night. The maximal movements of the eyeball to all sides-induced by yoga ocular training-can increase the maximal and continuous directional stretching of bulbomotor muscles that promote hemodynamic intraorbital circulation and hence more efficacious intra-orbital venous drainage. Dilated episcleral veins in response to heating or warming acquired from palming yogic technique may boost the aqueous ocular drainage that lowers IOP [16]. The used Yogic Tratak (continuous gaze to any small point or object following the flame of a candle) can contract and relax the ocular ciliary muscles producing an increase in the aqueous humor outflow; thus, IOP can be reduced in glaucomatous patients [10].

However, the improved IOP in response to Acu-TENS has not been justified in the literature, but the selected BL 61 and BL 62 acupoints for Acu-TENS in this study were based on the study by Yeh et al. [21] who reported non-significant changes to IOP in the sham Acu-TENS group while the study group who received the active Acu-TENS showed a significant decline in IOP in both eyes at all different time intervals (immediately, $30 \mathrm{~min}$, and $60 \mathrm{~min}$ after a $20 \mathrm{~min}$ session of Acu-TENS). This may have been due to the use of DC in acupoint stimulation via TENS, which rebalanced the 
Yin and Yang mechanisms within the eyes [21].

The BL 62 acupoint is routinely used in clinical practice to treat blurred vision, near-sightedness or myopia, retraction of upper eyelids, and incomplete closure of eyes following the paralysis of facial muscles. The main advantage that qualifies the common selection of BL 62 in the treatment of ocular disorders is the closely related location to the pathway of the Yang Heel Vessel (one of the extraordinary eight vessels that passes on the lateral side of the heel), which crosses the Yin Heel Vessel at the internal canthus of the eye [23].

BL62 is a fundamental acupoint that forms the eight acupoint confluence with SI3, LU7, SP4, GB41, TE5, PC6, and KI6. The eight acupoint confluence can treat all sorts of diseases because its stimulation can mobilize the qi within the 12 regular meridians [24] due to the unique location of eight acupoint confluence in the extremities that allow these points to connect the regular 12 meridians with the extraordinary eight meridians [25], so the selection of one acupoint of the eight acupoint confluence in clinical practice can be seen as a prerequisite for effective acupuncture treatment [24].

As one of the 13 ghost acupoints, the stimulation of BL62 can augment yin and yang balance, regulate Zang-Fu organs, unclose the orifices [26], improve the nourishment of the heart and spirit, and promote the flow of qi and blood to the ocular region, producing around-eye brightening and nourishment. Furthermore, through the regulation of defensive qi, stimulating BL62 helps to nourish the body and recover from eye diseases [23]. Regulated defensive energy (qi) flow in addition to the increased ocular blood supply around the ocular area may be the cause of lowered IOP in glaucomatous patients treated with Acu-TENS on the BL62 acupoint.

Supporting the results of this study, due to the increased oxygenated ocular blood supply, $5 \mathrm{~min}$ [16] or $10 \mathrm{~min}$ [27] of yoga ocular exercise combined with relaxed breathing techniques reduced IOP in healthy subjects. Furthermore, yoga ocular exercise may be a non-pharmacological therapy for ocular hypertension, especially after IOP reduction as seen in healthy undergraduate students who followed a $30 \mathrm{~min}$ yoga ocular exercise program (5 days a week for 6 weeks) [12]. Again, a 60 min-based interventional program of meditation (30 min) and yoga (slow deep relaxed breathing for $30 \mathrm{~min}$ ) for 21 consecutive days improved IOP due to the reduced oxidative and inflammatory markers along with the changed pattern of gene expression in POAG patients [17].

Yoga, on the opposite side, can elevate IOP approximately by two-folds during and after [28], particularly in glaucoma patients who trained via specific yogic positions as the headstanding position [14], downward-facing dog position, and forward-bend position [15].

\section{Trial limitations and recommended future studies}

The absence of follow-up is the main limitation of this study. Future studies in diabetic patients with POAG must focus on 1) IOP response in future long-term trials, 2) comparing the effects of Acu-TENS vs. yoga ocular exercise on IOP, and 3) evaluating the effects of other non-invasive acupoint stimulation modalities, such as laser acupuncture.

\section{CONCLUSIONS}

According to this short-term observation, the addition of Acu-TENS to yoga ocular exercise can reduce the high abnormal levels of IOP in diabetic patients with POAG. However, further long-term trial is needed.

\section{AUTHORS' CONTRIBUTIONS}

Authors contributed equally in conceiving the idea of research, conducting the treatment, collecting and analysis of data, writing and revising the manuscript. Both authors approved the final form of manuscript.

\section{CONFLICT OF INTEREST}

The authors declare no conflict of interest.

\section{ORCID}

Ali Mohamed Ali Ismail, https://orcid.org/0000-0003-1447-8817

Alshaymaa Shaaban Abd El-Azeim, https://orcid.org/0000-0002-3714-8776

\section{REFERENCES}

1. Ismail AMA. Hyperbaric oxygen therapy as a complementary or alternative therapy for chronic oral and gastrointestinal disorders: a narrative review. Int J Altern Complement Med 2020;1:33-40.

2. Ismail AMA, Abd Elfatah Abo Saif HF, El-Moatasem Mohamed AM. Effect of Jyoti-Trataka on intraocular pressure, autonomic control, and blood glucose in diabetic patients with high-tension primary open-angle glaucoma: a randomized-controlled trial. J Complement Integr Med 2021. doi: 10.1515/jcim-2021-0041. [Epub ahead of print]

3. Prum BE Jr, Rosenberg LF, Gedde SJ, Mansberger SL, Stein JD, Moroi SE, et al. Primary open-angle glaucoma preferred practice pattern $^{\circledast}$ guidelines. Ophthalmology 2016;123:P41-111.

4. Gagrani M, Faiq MA, Sidhu T, Dada R, Yadav RK, Sihota R, et al. Meditation enhances brain oxygenation, upregulates BDNF 
and improves quality of life in patients with primary open angle glaucoma: a randomized controlled trial. Restor Neurol Neurosci 2018;36:741-53.

5. Jung Y, Han K, Park HL, Park CK. Type 2 diabetes mellitus and risk of open-angle glaucoma development in Koreans: an 11-year nationwide propensity-score-matched study. Diabetes Metab 2018;44:328-32.

6. Hou H, Shoji T, Zangwill LM, Moghimi S, Saunders LJ, Hasenstab K, et al. Progression of primary open-angle glaucoma in diabetic and nondiabetic patients. Am J Ophthalmol 2018;189:1-9.

7. Vetrugno M, Uva MG, Russo V, Iester M, Ciancaglini M, Brusini $\mathrm{P}$, et al. Oral administration of forskolin and rutin contributes to intraocular pressure control in primary open angle glaucoma patients under maximum tolerated medical therapy. J Ocul Pharmacol Ther 2012;28:536-41.

8. Parikh RS, Parikh SR. Alternative therapy in glaucoma management: is there any role? Indian J Ophthalmol 2011; 59(Suppl1):S158-60.

9. Dada T, Mittal D, Mohanty K, Faiq MA, Bhat MA, Yadav RK, et al. Mindfulness meditation reduces intraocular pressure, lowers stress biomarkers and modulates gene expression in glaucoma: a randomized controlled trial. J Glaucoma 2018;27:1061-7.

10. Ismail AMA. Physical training and ocular yogic exercise in home: good alternative options to control the high-tension form of primary open angle glaucoma during the repeated COVID-19 waves. Int Marit Health 2021;72:243-4.

11. Rhee DJ, Spaeth GL, Myers JS, Steinmann WC, Augsburger JJ, Shatz LJ, et al. Prevalence of the use of complementary and alternative medicine for glaucoma. Ophthalmology 2002;109: 438-43.

12. Gupta SK, Aparna S. Effect of yoga ocular exercises on intraocular pressure. Yoga Mimamsa 2019;51:48-53.

13. Krieglstein GK, Waller WK, Leydhecker W. The vascular basis of the positional influence of the intraocular pressure. Albrecht Von Graefes Arch Klin Exp Ophthalmol 1978;206:99-106.

14. Baskaran M, Raman K, Ramani KK, Roy J, Vijaya L, Badrinath SS. Intraocular pressure changes and ocular biometry during Sirsasana (headstand posture) in yoga practitioners. Ophthalmology 2006;113:1327-32.

15. Jasien JV, Jonas JB, de Moraes CG, Ritch R. Intraocular pressure rise in subjects with and without glaucoma during four common yoga positions. PLoS One 2015;10:e0144505.

16. Dimitrova G, Trenceva A. The short-term effect of yoga ocular exercise on intra-ocular pressure. Acta Ophthalmol 2017;95:e81-2. 17. Dada T, Faiq MA, Mohanty K, Mittal D, Bhat M, Yadav $\mathrm{RK}$, et al. Effect of yoga and meditation based intervention on intraocular pressure, quality of life, oxidative stress and gene expression pattern in primary open angle glaucoma: a randomized controlled trial. Invest Ophthalmol Vis Sci 2016; 57(12).

18. Law SK, Wang L, Li T. Acupuncture for glaucoma. Cochrane Database Syst Rev 2020;2:CD006030.

19. Subbulakshmi R, Sivakumar G, Murthy SN. Acu-TENS stimulation at bilateral Zusanli (ST36) acupoint in Streptozotocin induced diabetic rats. Int J Pharm Sci Res 2018;9:477074.

20. Lau KS, Jones AY. A single session of Acu-TENS increases FEV1 and reduces dyspnoea in patients with chronic obstructive pulmonary disease: a randomised, placebo-controlled trial. Aust J Physiother 2008;54:179-84.

21. Yeh TY, Lin JC, Liu CF. Effect of transcutaneous electrical nerve stimulation through acupoints of Pucan (BL 61) and Shenmai (BL 62) on intraocular pressure in patients with glaucoma: a randomized controlled trial. J Tradit Chin Med 2016;36:51-6.

22. Sanchez I, Martin R. Advances in diagnostic applications for monitoring intraocular pressure in Glaucoma: a review. J Optom 2019;12:211-21.

23. Luo X. Clinical application of acupoint Shenmai (BL 62). J Acupunct Tuina Sci 2007;5:198-99.

24. Slopek A, Feng H. Eight-points-acupuncture and ancient Chinese contraindications in acupuncture: two methods of improving acupuncture treatment based upon ancient Chinese sources, and clinical experiences. J Acupunct Tuina Sci 2006;4: $321-4$.

25. Li X. Comments on the Specific acupoints--my experiences about the application of eight confluence acupoints. Zhen Ci Yan Jiu 2002;27:296-7.

26. Li N, Li J, Liu Z, Zhao Y, Jin B, Fu W, et al. Clinical observation on acupuncture at thirteen ghost acupoints for children with autism spectrum disorder. J Acupunct Tuina Sci 2017;15:344-8.

27. Galina D, Etsuo C, Takuhei S, Kanno J, Antonela L, Olivera L, et al. Immediate effect of yoga exercises for eyes on the macular thickness. Int J Yoga 2020;13:223-6.

28. Cramer H, Krucoff C, Dobos G. Adverse events associated with yoga: a systematic review of published case reports and case series. PLoS One 2013;8:e75515. 